\title{
Experimental Investigation on Formation and Evolution Characteristics of Frozen Wall under Salty Groundwater Seepage
}

\author{
B. Qin ${ }^{1}$, D. H. Rui ${ }^{1}$, S. R. Wang ${ }^{1,2^{*}}$, M. C. Ji ${ }^{1}$, and Z. S. Zou ${ }^{1}$ \\ ${ }^{1}$ International Joint Research Laboratory of Henan Province for Underground Space Development and Disaster Prevention, \\ Henan Polytechnic University, Jiaozuo 454003, China \\ ${ }^{2}$ School of Minerals and Energy Resources Engineering, University of New South Wales, Sydney, NSW 2052, Australia
}

Received 6 October 2020; Accepted 13 December 2020

\begin{abstract}
To investigate the groundwater influence on the performance of artificial freezing wall, especially the higher salt concentration in groundwater, a double-pipe seepage-freezing model test system was established to analyze the effects of different seepage velocities and salt concentrations on the formation of frozen walls. Results show that the frozen wall is uneven under seepage, and the thickness of the upstream frozen wall is small when the downstream is large. The salt concentration affects the development of the frozen wall, and the thickness of the frozen wall decreases with the increase of salt concentration. The maximum reduction rate of the frozen wall thickness is about $80.4 \%$ in upstream and $59.5 \%$ in downstream. As the flow velocity and salt concentration increase during the freezing process, the decrease rate of the seepage flow slows down, which in turn makes the freezing front expand slowly and closure time of the frozen wall extends. The conclusions obtained in this study can provide a theoretical reference for the design and construction of the similar engineering.
\end{abstract}

Keywords: Seepage-freezing model, Seepage velocity, Salt concentration, Frozen wall, Artificial freezing

\section{Introduction}

Artificial ground freezing (AGF) technology was initially used for the construction of shafts in soft soils in water-rich areas [1]. Since the frozen soil wall formed by AGF has good water sealing effect and mechanical strength, which is widely used in the construction of unstable strata such as water-rich, soft, broken, and quicksand [2]. However, in the freezing project, due to natural factors and man-made reasons resulting in high groundwater flow rate, which makes the frozen wall difficult to enclose and affects the safety of the project [3].

Recently, in the construction of AGF in coastal areas, due to the influence of seawater deposition environment, seawater impregnation and tides, the groundwater in this area has high salinity and high flow velocity, which seriously affects the formation and development of freezing walls. For example, in 2006, the AGF was used in the construction of the connecting passage between the South Building of Tianjin Metro Line 2 and Tucheng District, because the stratum in this section is mainly Quaternary river floodplain facies sediments, and its void ratio and water content are large. In addition, there is a phenomenon of transgression in this area, and the groundwater velocity is high, resulting in a slower growth rate of the frozen wall during the freezing method construction process.

Therefore, it is of significant to explore the development characteristics of artificial freezing temperature field under the condition of salty groundwater seepage, which can provide the reference for similar artificial freezing projects.

*E-mail address: w_sr88@163.com

ISSN: 1791-2377 @ 2020 School of Science, IHU. All rights reserved. doi:10.25103/iestr.136.14

\section{State of the art}

To explore the formation and development of frozen wall under seepage conditions, many scholars have conducted considerable related research [4-8]. Pimentel et al. developed a large-scale physical model under high seepage flow velocities, measured the distribution of temperature field under different seepage velocity conditions, and obtained the relationship between the measured cooling power and the energy required for calculation and time [9]. Sudisman et al. investigated the effect of water flow on the heat distribution and hydraulic conductivity of sand during freezing and thawing combined with infrared thermography [10-11]. Based on the similarity model theory, Li et al. established a double-row frozen pipe model test system under seepage conditions and conducted orthogonal experimental studies on the main factors affecting the formation of frozen wall [12]. Yang et al. carried out a model tests and numerical simulations to explore the influence of different seepage velocities and two freezing pipe spacingson the AGF applied in the coarse-grained soil layer [13]. Wang et al. constructed the large-scale hydrothermal coupled physical model and studied the temporal and spatial evolution of the temperature field of a single freezing pipe inhigh-velocity infiltration formation [14]. Rouabhi et al. deduced a fully coupled heat and mass transfer formulation considering the influence of salinity, and verified the salinity effect through laboratory experiments [15].

In terms of numerical simulation and coupled equations, Harlan presented a heat and fluid flow-coupled mathematical model to analyze the heat-fluid phenomenain frozen soil [16]. Vitel et al. developed a fully consistent coupled thermodynamic numerical model to simulate the freezing 
process of saturated non-deformable porous media under seepage conditions, which was also validated by threedimensional freezing tests under high seepage velocity conditions [17-18]. Tan et al. established thermo-hydro coupling governinge quations, they studied the effects of heat conduction, latent heat, and seepage velocity on temperature distribution and water migration [19]. Huang et al. established a coupled hydrothermal model considering water/ice phase transition to simulate the influence of water flow on the freezing process and proposed a new combining optimization method for freeze pipe arrangement considering water flow [20]. $\mathrm{Hu}$ et al. regarded a metro tunnel as an example, and they analyzed the coupled process of heat transfer and groundwater flow with phase change based on the theories of heat transfer in a porous medium and groundwater flow [21]. Tounsi et al. deduced a fully coupled thermal-hydraulic-mechanical model considering the salinity effect [22]. The related studies have obtained meaningful results [23-27].

However, there are few studies on the formation of frozen wall by saline groundwater seepage. Therefore, based on the similarity theory, a double-pipe seepage-freezing model test system was established to investigate the formation of frozen wall under different seepage velocity and salt concentration $\left(\mathrm{CaCl}_{2}\right)$ conditions. The research results can provide the theoretical reference for the design and construction of AGF in water-rich with salty sand layer.

The rest of this study is organized as follows. Section 3 describes the materials and methods. Section 4 gives the results and discussion, and finally, the conclusions are summarized in Section 5.

\section{Methodology}

\subsection{Soil samples}

The ISO (International Organization for Standardization) standard sand was selected as the test soil sample to simulate the saturated sand layer. After the sand sample was prepared and mixed evenly, it was sealed and placed for 24 hours to completely ensure that the water content of the sample was uniform. Its physical parameters were as follows: the particle density of soil was $2.65 \mathrm{~g} / \mathrm{cm}^{3}$, the water content of sand layer after layered compaction was $21.9 \%$, the void ratio was 0.52 , the porosity was $34.2 \%$, and the permeability coefficient was $1.39 \times 10^{-4} \mathrm{~m} / \mathrm{s}$. The particle distribution is shown in Table 1.

Table 1. Particle distribution

\begin{tabular}{c|c|c|c|c|c|c}
\hline $\begin{array}{c}\text { Particle } \\
\text { size (mm) }\end{array}$ & 2.5 & 1.25 & 0.63 & 0.315 & 0.16 & $\begin{array}{c}\text { Less than } \\
0.16\end{array}$ \\
\hline $\begin{array}{c}\text { Percentage } \\
\text { less than a } \\
\text { certain size } \\
\mathbf{( \% )}\end{array}$ & 100 & 76.48 & 48.12 & 32.45 & 22.54 & 22.54 \\
\hline
\end{tabular}

\subsection{Experimental design}

\subsubsection{Similarity criterion and similarity reduction ratio}

The model test device is shown in Fig. 1. According to the similarity model theory, the following similarity ratio can be obtained through the dimensional analysis of the $\pi$ theorem. The geometric reduction ratio was $1: 10$. In this experiment, copper pipes of $\Phi 10 \mathrm{~mm} \times 1 \mathrm{~mm}$ were selected. According to the Fourier criterion, the time reduction ratio was 1:100. The temperature reduction ratio 1:1 was obtained by the Kosovic criterion. The similarity reduction ratio of the groundwater seepage velocity was 10:1. This experiment used saturated sand as the research object, so the material similarity ratio was $1: 1$.

\subsubsection{Experimental setup}

The model test device was composed of a test chamber, a water flow circulation system, a freezing system, and a data acquisition system. The size of the test chamber was 500 $\mathrm{mm} \times 220 \mathrm{~mm} \times 700 \mathrm{~mm}$ (length $\times$ width $\times$ thickness), the freezing pipes were made of $\Phi 10 \mathrm{~mm} \times 1 \mathrm{~mm}$ seamless copper pipes, the spacing was $90 \mathrm{~mm}$, and the thickness of the saturated sand layer was $300 \mathrm{~mm}$.

The test chamber included a water inlet room, a sample loading room, and water outlet room. The width of inlet and outlet water room was $100 \mathrm{~mm}$. The water inlet and outlet rooms were connected with the sample loading room through an acrylic plate with uniform open holes. The geotextile with a permeability coefficient greater than 0.10 $\mathrm{cm} / \mathrm{s}$ was pasted on the inside of the acrylic plate to prevent the fine particles of sand from being carried out by seepage water. To ensure the effective contact between the specimen and acrylic plate, the insides of the specimen room were roughened to prevent a preferential flow channel, which caused evident boundary effects on the test precision.

The seepage water circulation system consists of a constant head device, collecting buckets, a submersible pump, an electronic balance, and a computer. The constant water head device was composed of buckets 1 and 2, and corresponding PVC pipes, which was shown in Fig. 1. In the test, the submersible pump was used to continuously supply seepage water to bucket 1 to keep bucket 1 overflowing, and the overflowing water flowed back into bucket 3 through the opening at the bottom of bucket 2 . The bottom of the bucket 1 barrel was connected to the water inlet room through a PVC pipe, which was kept full of flow in the test. The seepage velocity in the sand layer was controlled by adjusting the height of this head device to realize the model test of frozen wall formation under different seepage velocity conditions. The seepage velocity in the saturated sand layer could be calculated through the water head and the outlet flow rate. The outlet flow rate was determined by an electronic balance, which was connected to a computer through an RS232 interface. The acquisition frequency was twice a second to monitor the change of flow rate during the test. As a result, the correlation between head and flow velocity was determined. The relationship between groundwater seepage velocity, groundwater flow rate and head are as follows.

$$
\begin{aligned}
& \frac{v}{n}=V \\
& v=k \frac{\Delta H}{\Delta l}
\end{aligned}
$$

where, $n$ is the porosity of the porous medium, $v$ is the groundwater seepage velocity, $V$ is the groundwater flow velocity, $k$ is the permeability coefficient of the sand layer, $\Delta H$ is the head difference, and $\Delta l$ is the hydraulic path.

A $100 \mathrm{~mm}$ thick saturated clay was laid on top of the sand layer as a water barrier to prevent excessive water pressure from causing overflow on the top of the sand layer. The outside and bottom of the test chamber were wrapped with $5 \mathrm{~cm}$ thick insulation cotton, while the surrounding area was filled with $10 \mathrm{~cm}$ thick perlite as the insulation layer. 
The cold bath was connected to the freezing pipes to form a de-loop and the refrigerant temperature was set at $-20^{\circ} \mathrm{C}$.

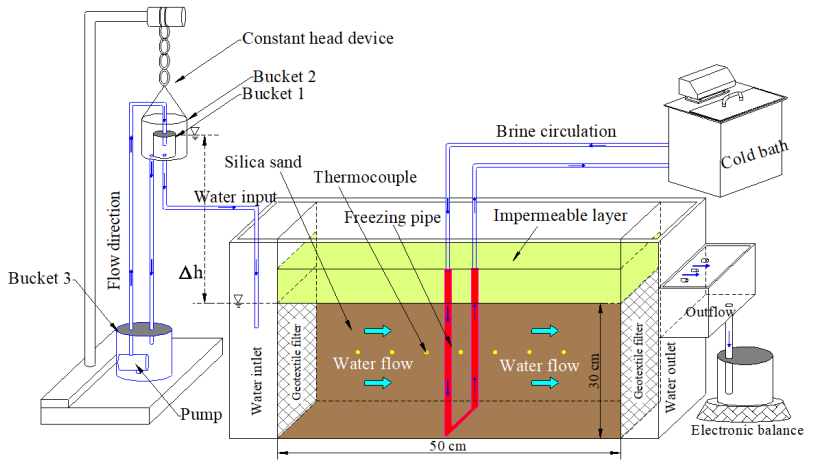

(a) Diagram of the seepage-freezing experimental apparatus

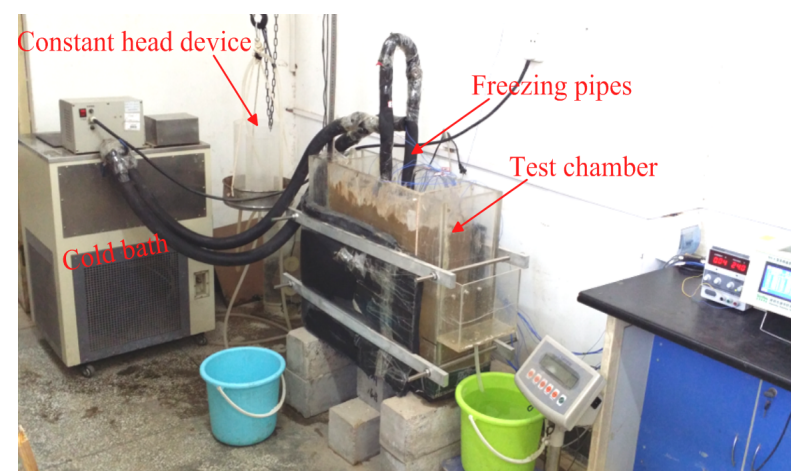

(b) Seepage-freezing experimental apparatus

Fig. 1. Seepage-freezing experimental apparatus in the laboratory.

\subsubsection{Arrangement of temperature measuring points}

The arrangement of measuring points is shown in Fig. 2. The SH-X-type multiplex temperature tester with K-type thermocouples was selected to monitor the temperature changes in the soil during the formation of the frozen wall. The resolution of temperature measurement was $0.1^{\circ} \mathrm{C}$, the range of temperature measurement was $-50{ }^{\circ} \mathrm{C}$ to $+120{ }^{\circ} \mathrm{C}$, and the precision was $\pm 0.2^{\circ} \mathrm{C}$. The temperature sensors were placed $15 \mathrm{~cm}$ along the depth of the soil. Four axes were divided according to the temperature measuring points and the arrangement of the freezing pipes, which were Path1, Path2, Path3, and Path4, respectively. The temperature of the point T8 at the junction of Path1 and Path2 was an important basis for judging the closure of the frozen wall, that is, the temperature of the point T8 was lower than the freezing point could be regarded as the beginning of the closure of the frozen wall.

The measurement points T1, T2, T3, T8, T11, T10, T9 were arranged in sequence along the Path1 axis. Along the Path2 direction. The temperature measuring points T7, T6, T8, T14, T15, and T16 were arranged successively from upstream to downstream. T4, T2, T5 and T12, T10, T13 were arranged successively in the direction of Path3 and Path4, where T2 and T10 were two thermocouple measuring points affixed to the freezing pipes.

\subsection{Experimental scheme}

\subsubsection{Freezing point of salinewater}

$\mathrm{CaCl}_{2}$ was selected to prepare seepage saline water in the experiment, and the mass concentrations of salt were $0 \%, 5$ $\%$, $15 \%$, $25 \%$, and $35 \%$, respectively. The freezing temperature of saline water was regarded as the temperature at which the sand began to freeze. The measuring method of saline water freezing point was to put an appropriate amount of saline into a $50 \mathrm{ml}$ centrifugal tube, and fix the thermocouple in it. Then the centrifugal tube was put into a cold bath with a set temperature for freezing. The temperature tester was set the acquisition frequency as $1 \mathrm{~s}$. The saline water would release latent heat when the waterice phase transition occurred, and the saline freezing point could be obtained by analyzing the strong phase transition region of the temperature curve. The freezing point of saline water decreased linearly with the increase of salt concentration, which can be seen from Fig. 3.

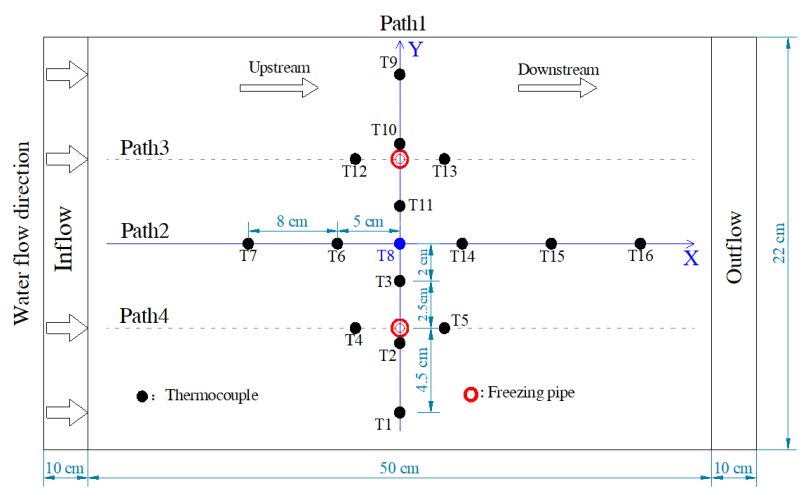

Fig. 2. Plane layout of temperature measuring points.

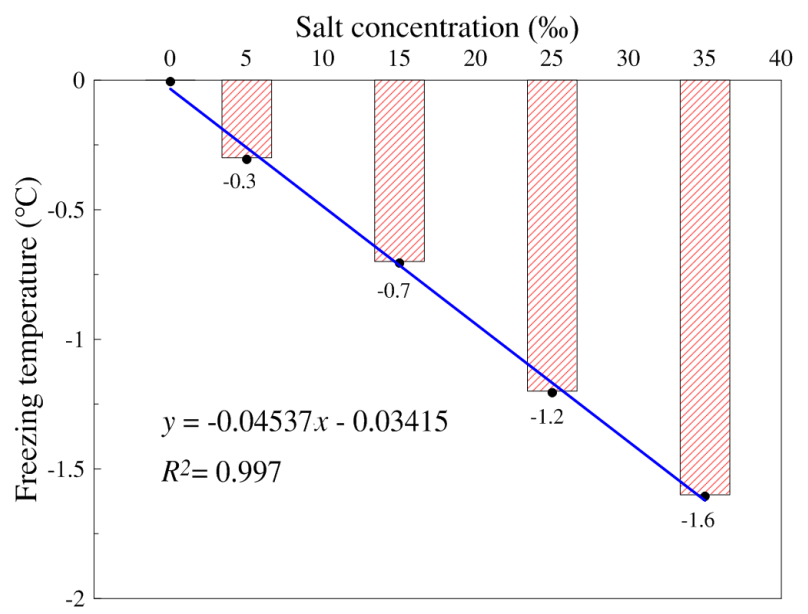

Fig. 3. Relationship between salt concentration and freezing point.

\subsubsection{Test process}

The test procedure was as following:

(1) Filled the prepared sand sample in layers and compact it until that reached the set height, and the thermocouples were buried in the predetermined position.

(2) Connected the seepage water circulation system to keep a certain height of water head unchanged to make it seepage. The permeability coefficient of the sand layer was determined by the constant head method after the inlet and outlet water was stable.

(3) After setting up the insulation layer, the cold bath which had been reduced to the predetermined temperature would be opened, and it started to circulate in the freezing pipes, then seepage-freezing test started.

(4) The sand layer would be thawed after freezing, and when the initial temperature was reached, the next set of tests would be started. 
Table 2. Experimental scheme.

\begin{tabular}{|c|c|c|c|c|c|c|c|c|c|}
\hline $\begin{array}{c}\text { Salt } \\
\text { concentratio } \\
\text { n (\%) }\end{array}$ & $\begin{array}{l}\text { Seepage } \\
\text { velocity } \\
(\mathbf{m} / \mathbf{d})\end{array}$ & $\begin{array}{c}\text { Salt } \\
\text { concentratio } \\
\text { n (\%) }\end{array}$ & $\begin{array}{l}\text { Seepage } \\
\text { velocity } \\
(\mathbf{m} / \mathbf{d})\end{array}$ & $\begin{array}{c}\text { Salt } \\
\text { concentratio } \\
\text { n (\%) }\end{array}$ & $\begin{array}{l}\text { Seepage } \\
\text { velocity } \\
(\mathbf{m} / \mathbf{d})\end{array}$ & $\begin{array}{c}\text { Salt } \\
\text { concentratio } \\
\text { n (\%) }\end{array}$ & $\begin{array}{l}\text { Seepage } \\
\text { velocity } \\
(\mathbf{m} / \mathbf{d})\end{array}$ & $\begin{array}{c}\text { Salt } \\
\text { concentratio } \\
\text { n (\%) }\end{array}$ & $\begin{array}{l}\text { Seepage } \\
\text { velocity } \\
(\mathbf{m} / \mathbf{d})\end{array}$ \\
\hline \multirow{4}{*}{0} & 0 & \multirow{4}{*}{5} & 0 & \multirow{4}{*}{15} & 0 & \multirow{4}{*}{25} & 0 & \multirow{4}{*}{35} & 0 \\
\hline & 3.5 & & 3.5 & & 3.5 & & 3.5 & & 3.5 \\
\hline & 4.5 & & 4.5 & & 4.5 & & 4.5 & & 4.5 \\
\hline & 5.5 & & 5.5 & & 5.5 & & 5.5 & & 5.5 \\
\hline
\end{tabular}

\section{Results and discussion}

\subsection{Change of freezing temperature field}

As shown in Fig. 2, the Path1 axis is on the line connecting the two freezing pipes. The Path2 axis is consistent with the central axis in the length direction of the test chamber, which is the vertical bisector of the Path1 axis. The temperature of T8 at the intersection of the two axes is an important basis for judging the closure of the frozen wall, that is, the frozen wall is considered to be enclosed when the temperature of the $\mathrm{T} 8$ is below the freezing point.

\subsubsection{Analysis of temperature change of measuring point under hydrostatic condition}

Under hydrostatic condition, the temperature changes of two groups of experiments with salt concentrations of 0 and 15 \%o were compared and analyzed.

Fig. 4 shows the temperature change of each measuring point on the Path2 axis with time under hydrostatic condition and salt concentrations of 0 and $15 \%$. The solid mark showed the temperature change of each measuring point when the salt concentration was 0 , while the hollow mark referred to the situation when the salt concentration was $15 \%$. As shown in Fig. 4, in the saturated sand layer without groundwater flow, the temperature at each measuring point gradually decreased with the increase of the distance from the freezing pipes, and the cooling rate also had the same trend. The cooling rule of the measuring point located at the symmetrical position of the upstream and downstream on the Path2 axis was basically the same. When the salt concentration increased to $15 \%$, the temperature at the same measuring point was lower than that when the salt concentration was 0 . According to the fitting curve, the cooling rule of each point showed an exponential distribution. The cooling rate was fast during the active freezing period, and then the temperature changed slowly during the stable freezing period. The fitting functions are shown in Table 3.

$y=\mathrm{a}-\mathrm{b} \cdot \mathrm{c}^{x}$

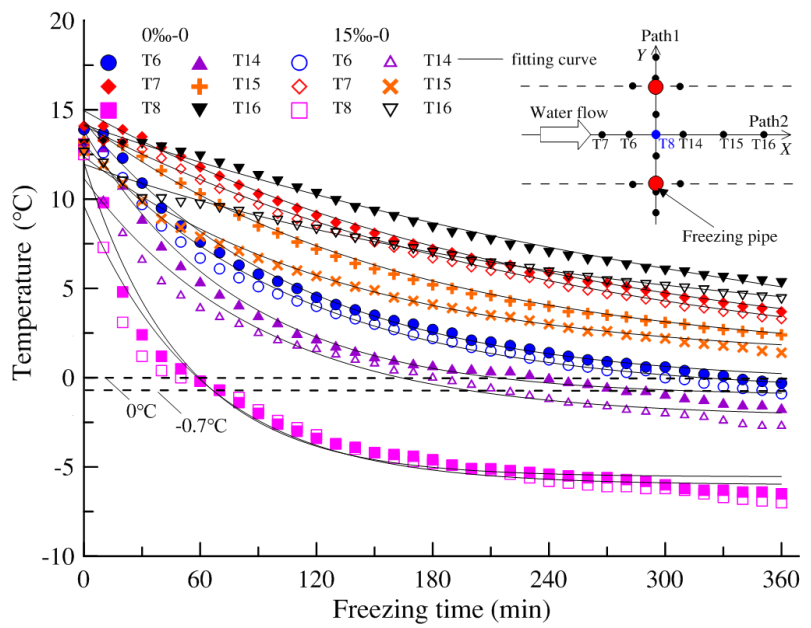

Fig. 4. Temperature change of measuring points on Path2 axis.

Table 3. Experimental scheme.

\begin{tabular}{|c|c|c|c|c|c|c|c|c|c|c|c|c|}
\hline \multirow{2}{*}{$\begin{array}{c}\text { Poin } \\
t\end{array}$} & \multirow{2}{*}{$\begin{array}{l}\text { Salt } \\
\text { (\%o) }\end{array}$} & \multirow{2}{*}{$f(x)$} & \multicolumn{3}{|c|}{ Parameters } & \multirow{2}{*}{$R^{2}$} & \multirow{2}{*}{$\begin{array}{l}\text { Salt } \\
(\% 0)\end{array}$} & \multirow{2}{*}{$f(x)$} & \multicolumn{3}{|c|}{ Parameters } & \multirow[b]{2}{*}{$R^{2}$} \\
\hline & & & $\mathrm{a}$ & $\mathrm{b}$ & $\mathrm{c}$ & & & & $\mathrm{a}$ & $\mathrm{b}$ & $\mathrm{c}$ & \\
\hline T1 & & & -2.197 & -15.428 & 0.987 & 0.970 & & & -3.061 & -14.020 & 0.988 & 0.961 \\
\hline $\mathrm{T} 3$ & & & -5.495 & -17.265 & 0.981 & 0.969 & & & -5.961 & -14.937 & 0.984 & 0.949 \\
\hline $\mathrm{T} 4$ & & & -3.586 & -15.536 & 0.984 & 0.971 & & & -3.889 & -14.113 & 0.985 & 0.965 \\
\hline T5 & & & -2.445 & -15.372 & 0.986 & 0.985 & & & -3.141 & -13.424 & 0.987 & 0.969 \\
\hline T6 & . & $y=\mathrm{a}-\mathrm{b} \cdot \mathrm{c}^{3}$ & -0.336 & -14.686 & 0.991 & 0.995 & 15 & $y=\mathrm{a}-\mathrm{b} \cdot \mathrm{c}^{x}$ & -0.846 & -13.928 & 0.991 & 0.993 \\
\hline $\mathrm{T} 7$ & 0 & & 0.871 & -14.079 & 0.996 & 0.998 & 15 & & 0.198 & -13.924 & 0.996 & 0.997 \\
\hline T8 & & & -5.556 & -17.585 & 0.981 & 0.971 & & & -6.008 & -15.636 & 0.984 & 0.944 \\
\hline $\mathrm{T} 14$ & & & -1.030 & -14.843 & 0.988 & 0.990 & & & -2.232 & -13.392 & 0.989 & 0.978 \\
\hline $\mathrm{T} 15$ & & & 1.046 & -13.290 & 0.994 & 0.997 & & & 1.042 & -11.340 & 0.993 & 0.995 \\
\hline $\mathrm{T} 16$ & & & -1.581 & -15.750 & 0.998 & 0.990 & & & 2.065 & -9.891 & 0.996 & 0.990 \\
\hline
\end{tabular}

Fig. 5 shows the temperature change of each measuring point on the Path1 axis under hydrostatic condition and salt concentration of 0 and $15 \%$. T2 and T10 were two thermocouples affixed to the surface wall of the freezing pipes. According to the cooling curve, there was a temperature difference between the inflow and outflow of the refrigerant, the reason was that cold exchange existed between the refrigerant and the sand during freezing. The outside temperature of the two freezing pipes was that the temperature at $\mathrm{T} 1$ was slightly higher than that at $\mathrm{T} 9$, which was consistent with the temperature at $\mathrm{T} 2$ slightly higher than that at T10. Under the hydrostatic conditions, the sand inside the freezing pipes gradually frozen and enclosed. Due to the sufficient supply of cooling capacity and the only heat conduction between the freezing pipes and the sand layer, the temperatures of the three measuring points T3, T8 and T11 tended to be the same. The cooling rule of each point attenuated exponentially with time, and the fitting function is also shown in Table 3. 


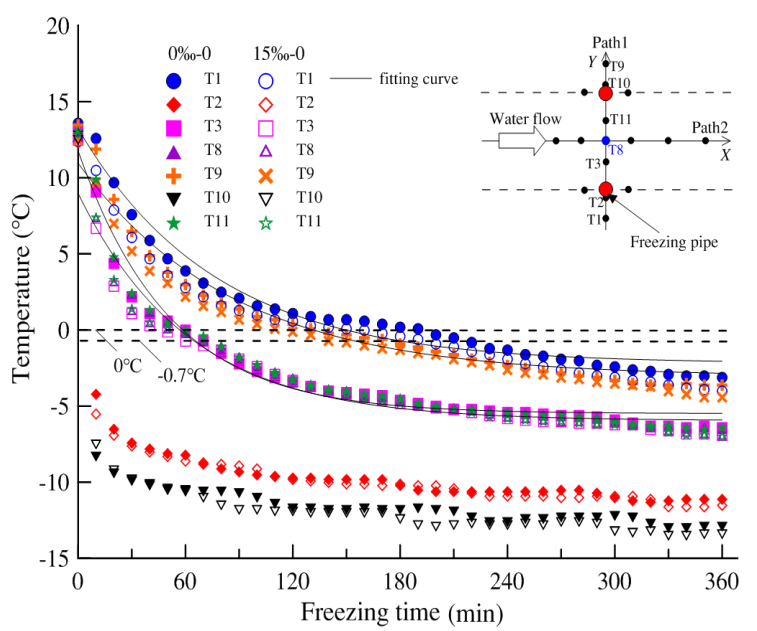

Fig. 5. Temperature change of measuring points on Path1 axis.

The temperature of the measuring point on the Path 3 and Path4 axes varies as shown in Fig. 6. Under the hydrostatic condition, the temperature development rule of the symmetrically distributed measuring points on both sides of the two freezing pipes was basically the same, when the salt concentration was $15 \%$, the temperature of each point was slightly lower than that when the salt concentration was 0 . During the freezing process, the cooling curve of each point still attenuated exponentially, and the fitting curves of T4 and $\mathrm{T} 5$ could represent the cooling trend of each point on the two axes. The temperature of T12 and T13 was slightly lower than that of $\mathrm{T} 4$ and $\mathrm{T} 5$ at the same time, which was caused by the temperature difference between the inflow and outflow of refrigerant.

\subsubsection{Analysis of temperature change of measuring} points under seepage condition

Fig. 7. shows the variation of temperature at the measuring point on the Path2 axis under seepage conditions. When the seepage velocity increased from 0 to $3.5 \mathrm{~m} / \mathrm{d}$, the temperature at $\mathrm{T} 7$ in the upstream area increased significantly, which indicated that it was difficult to conduct the cold energy to upstream generated by the freezing pipes under the action of seepage. The reason was that the cold energy conducted upstream by the freezing pipes was offset by the convective heat transfer of seepage water. When the seepage velocity increased from $3.5 \mathrm{~m} / \mathrm{d}$ to $5.5 \mathrm{~m} / \mathrm{d}$, the temperature at $\mathrm{T} 7$ didn't change obviously but decreased gradually. When the seepage velocity increased from 0 to $5.5 \mathrm{~m} / \mathrm{d}$, the temperature change at T8 was greater than that at T14, especially when the velocity increased from 0 to $3.5 \mathrm{~m} / \mathrm{d}$, which indicated that the flow had obvious convective heat transfer and brought the cold energy from T8 point to downstream. The temperature curve of T16 showed that the cooling curve under hydrostatic condition was slow and the temperature was higher than that of seepage, indicated that the saline water flowing through T16 was cooled by convective heat transfer, which led to convective heat transfer with sand layer in the downstream area where heat conduction was difficult to reach, so that the downstream temperature was reduced.

The Path1 axis was symmetrical with respect to T8, and the temperature drop of each point of phase symmetry was basically the same. Under the condition of seepage, the temperatures of T1, T2, T3 and T8 were selected for analysis, as shown in Fig. 8. With the increase of seepage velocity, the minimum temperature of $\mathrm{T} 1$ on the outside of freezing pipes increased. When the seepage velocity occurred, the temperature development of $\mathrm{T} 1$ was greatly limited. The temperature variation of $\mathrm{T} 3$ was similar to that of T8. With the increase of seepage velocity, the temperature drop curves of both points were suppressed. Under the action of seepage, the temperature of $\mathrm{T} 2$ on the surface of freezing pipe increased with the increase of seepage velocity, which indicated that the higher the flow velocity was, the more intense the convective heat transfer was.

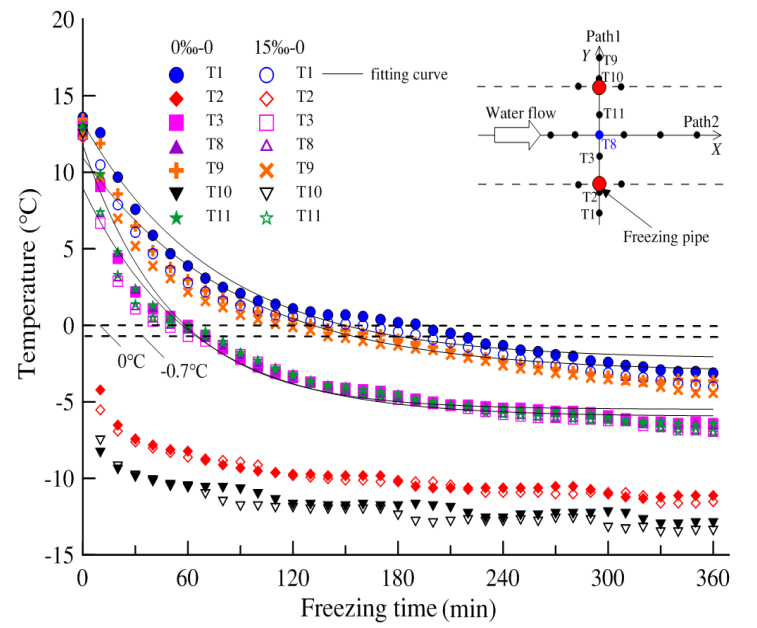

Fig. 6. Temperature curves of measuring points on Path 3 and Path 4 axis.

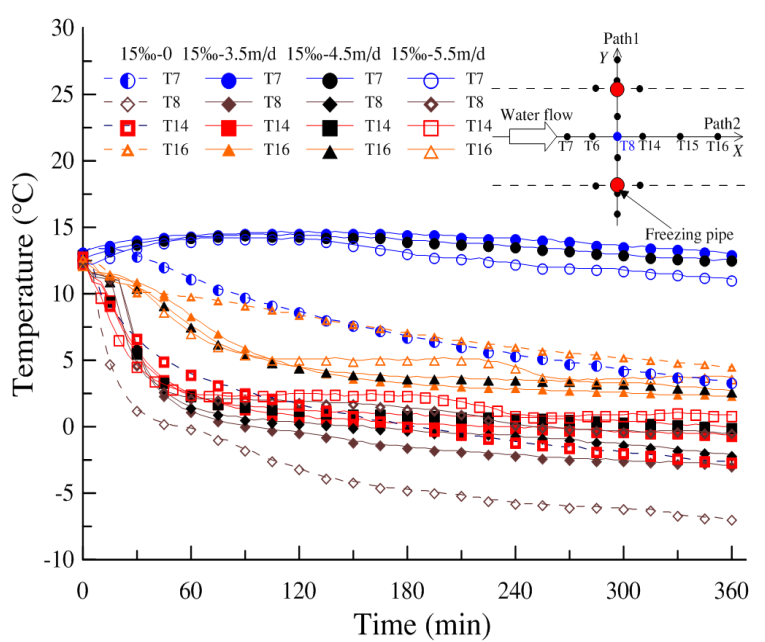

Fig. 7. The temperature change of measuring points on Path 2 under the condition of seepage.

The temperature change of measuring points T10, T12 and T13 on Path3 axis are shown in Fig. 9. The rule of temperature drop at T10 was the same as that at T2. The temperature variation range of $\mathrm{T} 12$ in the upstream region was larger than that of the symmetry point T13. When the seepage velocity increased from 0 to $3.5 \mathrm{~m} / \mathrm{d}$, the temperature at $\mathrm{T} 12$ increased obviously, all above $0{ }^{\circ} \mathrm{C}$, indicating that the development of the upstream temperature field was greatly restrained under the action of seepage. Compared with the temperature change at T13, it showed that the negative temperature zone of the freezing temperature field shifted downstream under the condition of seepage.

\subsubsection{Closure time of the frozen wall}

The closure time of frozen wall under the condition of different seepage velocities and salt concentrations is shown in Fig. 10. As seen from Fig. 10, with the increase of seepage velocity and salt concentration, the closure time of 
frozen wall increased obviously, and the effect of seepage velocity on the closure of frozen wall was more significant. When the seepage velocity was constant, the closure time was prolonged with the increase of salt concentration, indicating that the salt had an inhibitory effect on the expansion of the freezing front. With the increase of salt concentration of seepage water, the physical parameters such as freezing point, thermal conductivity and specific heat capacity all decreased. The changes of these parameters resulted in the weakening of heat conduction and convective heat transfer in the freezing process, which led to the prolongation of the closure time of frozen wall. When the seepage velocity increased to $5.5 \mathrm{~m} / \mathrm{d}$ and the salt concentration increased to $25 \%$, the frozen wall could not enclose.

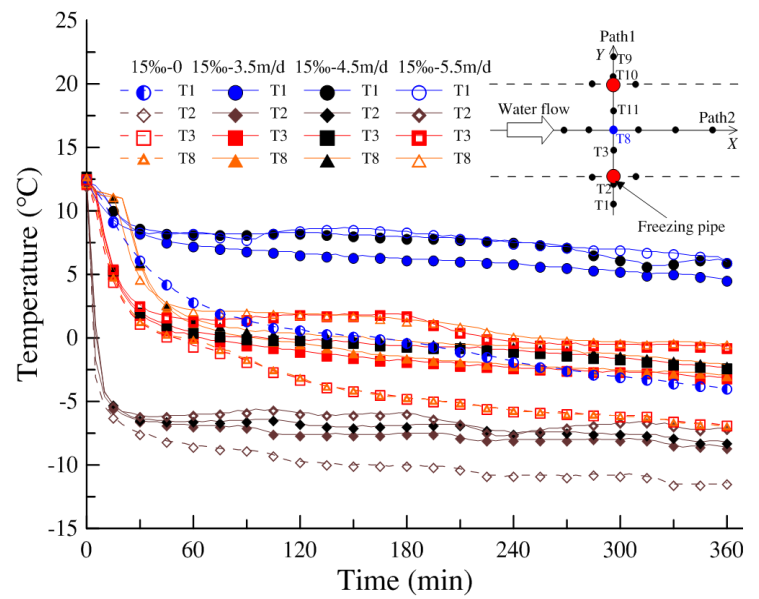

Fig. 8. The temperature change of measuring points on Path2 under the condition of seepage.

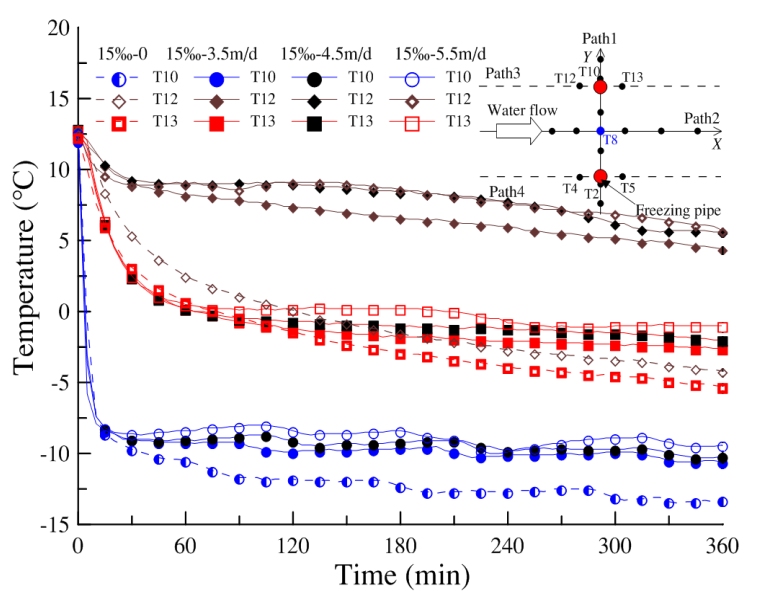

Fig. 9. The temperature change of measuring points on Path 3 under the condition of seepage.

\subsection{Spatial distribution analysis of freezing temperature 4.2.1 Distribution of temperature field}

The surfer software was used to draw the isotherm diagram of the temperature field after freezing for 6 hours, as shown in Fig. 11. It could be seen that the temperature field under seepage condition was no longer symmetrically distributed along the Path1 axis, the range of the upstream cooling zone was smaller than that of the downstream region, the temperature of the downstream region was lower than that of the upstream region. The greater the seepage velocity was, the greater the difference between the upstream and downstream was. Because of the effect of seepage, the sand layer in the upstream area that should have been cooled by the heat conduction of the freezing pipes being offset by the convective heat transfer effect of the saline water. After the saline water flowed through the upstream, the temperature decreased, and when it flowed through the downstream area, the convective heat transfer was weakened. Therefore, the cooling efficiency of the sand layer in the downstream area was higher than that in the upstream area. However, with the increase of seepage velocity, the cooling efficiency of the whole temperature field in the freezing process was weakened, and the expansion range of the freezing front upstream was smaller than that downstream. It could be seen from the figure that the temperature field was symmetrically distributed along the Path2 axis. However, the reason for the incomplete symmetrical distribution of the temperature field was that the temperature of the de-loop refrigerant in the freezing pipes in the two-hole freezing model was different. From the isotherm diagram, it could be seen that the frozen wall thickness decreased with the increase of seepage velocity, and the frozen wall thickness was weakened by the increase of salt concentration in seepage water.

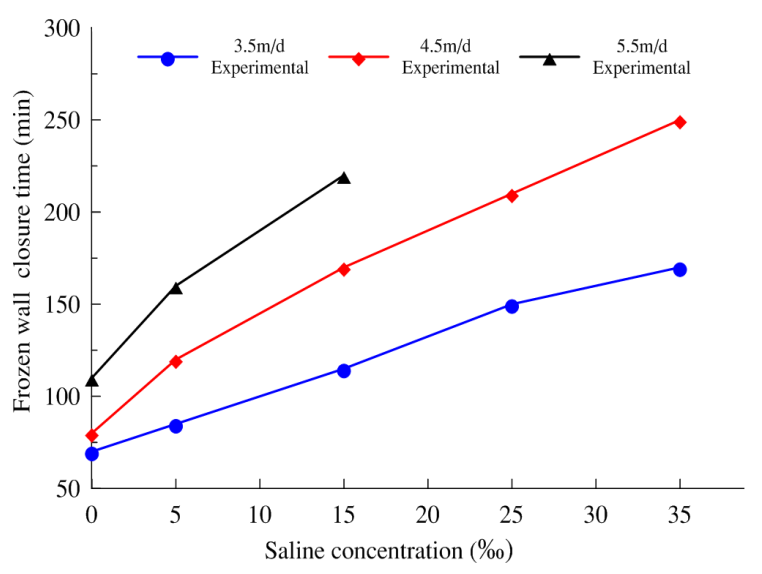

Fig. 10. Closure time of the frozen wall.

\subsubsection{Analysis of frozen wall thickness}

The change of frozen wall thickness on Path2 axis under different seepage velocities and salt concentration is shown in Fig. 12. The seepage of salt-bearing groundwater led to the uneven development of the upstream and downstream frozen wall, and the thickness of the downstream frozen wall was obviously larger than that of the upstream frozen wall. The reason was the convective heat transfer of saline water seepage changed the spatial distribution of cooling capacity in the frozen zone of sand layer, the cold energy of the freezing pipes to the upstream was carried downstream by saline water. As seen from Fig. 12, the thickness of the frozen wall was 0 when the seepage velocity was $5.5 \mathrm{~m} / \mathrm{d}$ and the salt concentration was $15 \%$, which indicated that the frozen wall could not enclose in this case.

With the increase of seepage velocity, the thickness of upstream and downstream frozen wall decreased. According to the bar chart and solid lines, when the seepage velocity increased from $4.5 \mathrm{~m} / \mathrm{d}$ to $5.5 \mathrm{~m} / \mathrm{d}$, the thinning rate of frozen wall was greater than that of seepage velocity from $3.5 \mathrm{~m} / \mathrm{d}$ to $4.5 \mathrm{~m} / \mathrm{d}$, which showed that the greater the seepage velocity, the stronger the inhibition of the freezing front. The maximum value was on the frozen wall thickness curve when the salt concentration was $15 \%$. That is, the maximum thinning rate in the frozen wall thickness occurred between the seepage velocities of $5.5 \mathrm{~m} / \mathrm{d}$ and $3.5 \mathrm{~m} / \mathrm{d}$. The maximum values of upstream and downstream were $74.1 \%$ and $59.6 \%$, respectively. 

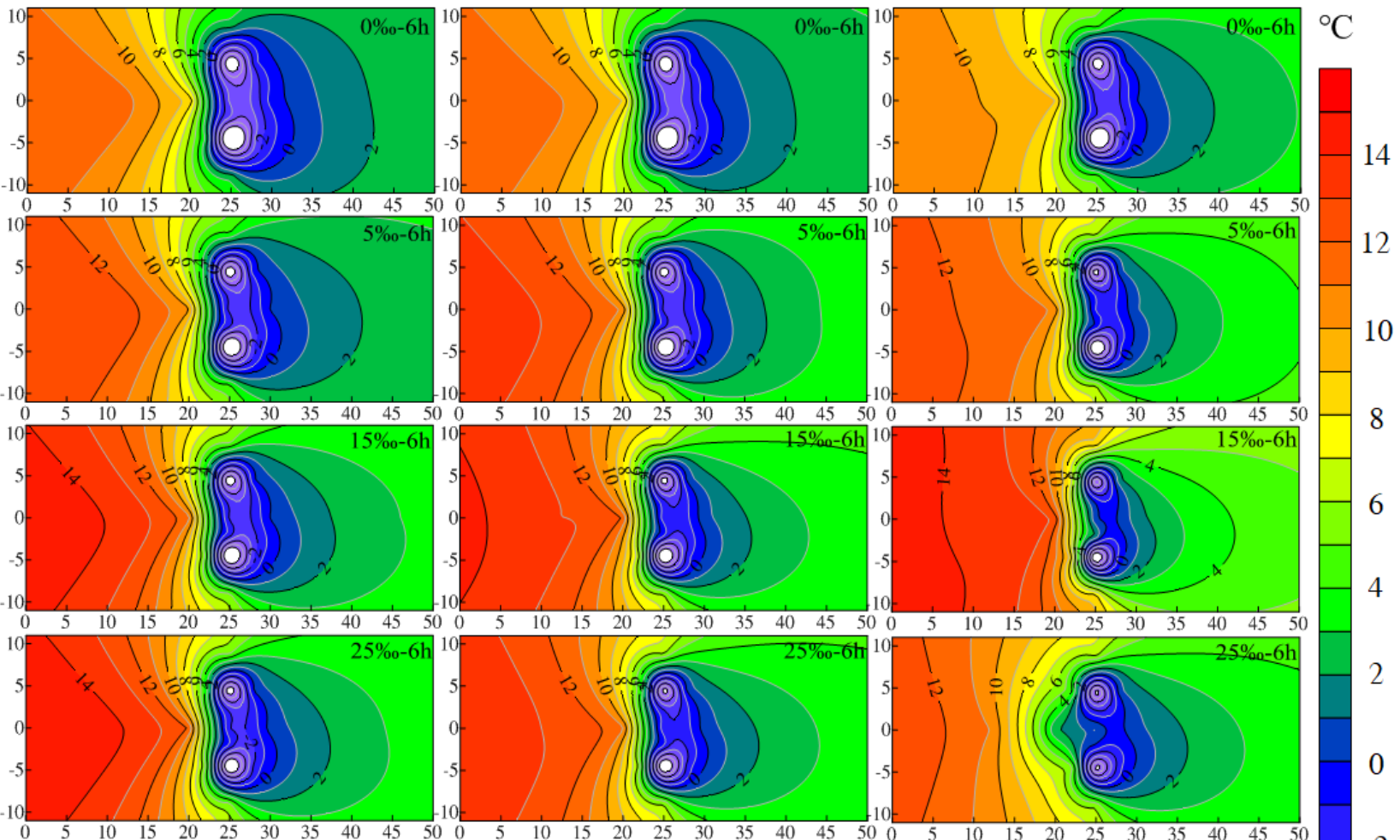

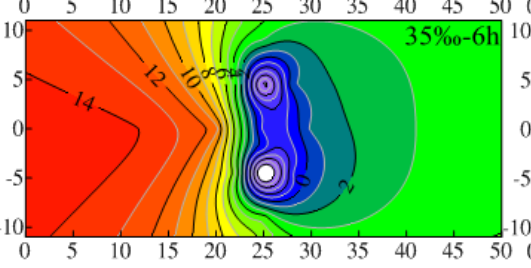

(a) $3.5 \mathrm{~m} / \mathrm{d}$

Fig. 11. Distribution of freezing temperature field.

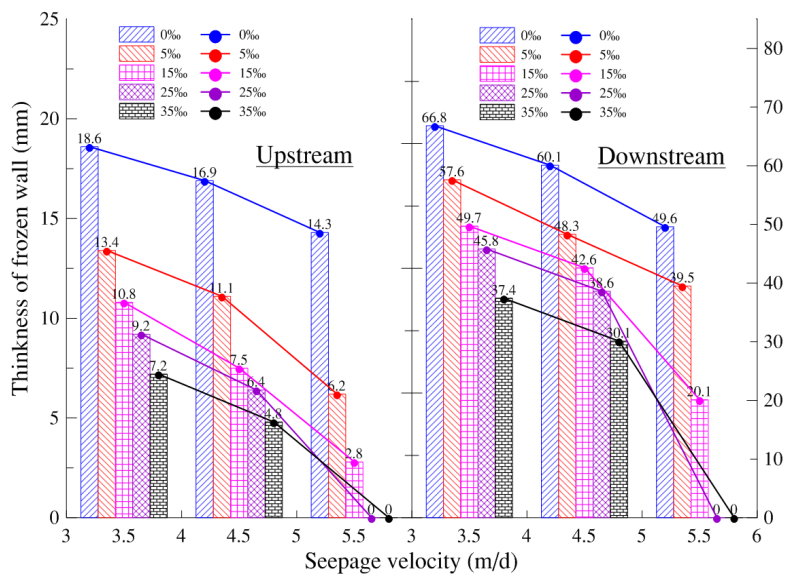

Fig. 12. Frozen wall thickness change.

Under certain velocity conditions, according to the bar chart, it could be seen that the thickness of the frozen wall decreased gradually with the increase of salt concentration, and the thinning rate decreased with the gradual increase of salt concentration. Compared with the bar charts at different seepagevelocities, it could be seen that the thinning rate of frozen wall increased with the increase of seepage velocity in the same interval. Under the double influence of seepage velocity and salinity, the inhibition of frozen wall expansion was more significant. When the seepage velocity was 5.5 $\mathrm{m} / \mathrm{d}$, the maximum percentage of reduction in the frozen wall thickness occurred between the salt concentrations of
$15 \%$ and 0 . The maximum values of upstream and downstream were $80.4 \%$ and $59.5 \%$, respectively.

The thinning rate of frozen wall refers to the ratio of the frozen wall thickness when the salt concentration or flow velocity was a certain value to that when the salt concentration or flow velocity was another value. The formula is as follows:

$R_{\mathrm{m} \rightarrow n}=\frac{\left|R_{m}-R_{n}\right|}{R_{n}} \times 100 \%$

where, $R_{m}$ is the frozen wall thickness when the salt concentration or seepage velocity is a certain value. $R_{n}$ is the frozen wall thickness when the salt concentration or seepage velocity is another value.

\subsection{Flow rate changes during freezing}

During the freezing process, the flow rate changes corresponding to different salt concentrations under different seepage velocity conditions are shown in Fig. 13.

As shown in Fig. 13, with the gradual increase of the seepage velocity, the flow rate of the seepage field gradually slowed down, and the greater the flow velocity, the smaller the decreased of the flow. When the seepage velocity was constant, with the increase of the salt concentration, the flow rate decreased gradually. When the salt concentration was $35 \%$, the flow rate decreased the slowest. The change of the flow rate was related to the expansion speed of the freezing front. The rapid change of the flow rate indicated that the 
corresponding freezing front moved faster, forming an impervious frozen wall to block the seepage of saline water. The slow decline rate of flow meant that the seepage of saline water had a longer time in the freezing zone, and the convective heat transfer time between the flow and the sand layer was prolonged, thus the closure time of the frozen wall was prolonged.

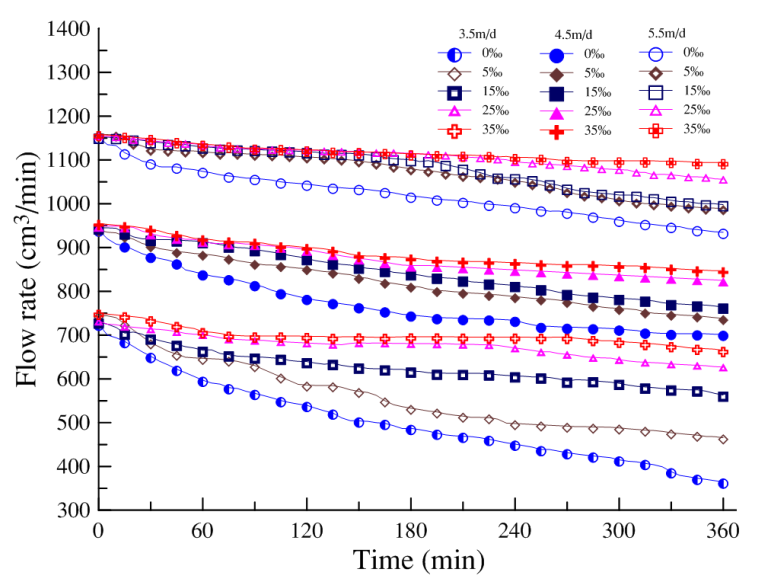

Fig. 13. Changes in flow rate during freezing.

During the double-pipe freezing process, the freezing fronts extended toward the middle area of the freezing pipes. With the continuous freezing, the freezing fronts formed by adjacent freezing pipes gradually enclosed and formed a whole, then the seepage of saline was blocked. However, the flow rate after the freezing front enclosed was not 0 , because on the outside of the double pipes, the expansion range of the frozen wall was limited, and a complete impervious frozen wall was not formed. The increase of flow velocity and salt concentration reduced the thickness of the frozen wall formed in the freezing process, increased the crosssection of the water, and slowed down the decreasing rate of flow rate.

\section{Conclusions}

To investigate the groundwater influence on the performance of artificial freezing wall, based on the Similarity criterion, the double-pipe seepage-freezing model test system was established to analyze the effects of different seepage velocities and salt concentrations on the formation of frozen wall. The main conclusions are as follows:

(1) The temperature field shows the axisymmetric distribution with respect to Path1 under the hydrostatic conditions, while under the action of saline water seepage, the temperature field is no longer symmetrically distributed about Path1 axis. Both salt concentration and seepage velocity can inhibit the expansion of freezing front and prolong the closure time of the frozen wall. Within the influence range of freezing, the temperature exponentially attenuates with freezing.

(2) Under the seepage condition, the cooling efficiency of the freezing temperature field is weakened, and the expansion range of the freezing front in the upstream is smaller than that in the downstream. The seepage of saline water changes the spatial distribution of the cold energy capacity in the frozen zone, the thickness of the frozen wall in the downstream is greater than that in the upstream. With the increase of the salt concentration, the thickness of the frozen wall decreases gradually.

(3) The decrease of the flow rate during the freezing process can be delayed by the increase of the seepage velocity and salt concentration. The increase of the seepage velocity and salt concentration can thin the frozen wall formed in the upstream and downstream, which increases the cross-section of the water and then slows down the decline rate of the flow rate. The decreased flow rate can slow the freezing front expands and prolong the closure time of the frozen wall.

Aiming at the current problems of high groundwater velocity and high salinity in coastal areas that cause freezing difficulties, this study has made a targeted test study, which can provide a reference for the similar artificial freezing projects. However, in the further study, the numerical simulation will be combined to optimize the influence of flow velocity and salt concentration on the formation and evolution of frozen wall.

\section{Acknowledgements}

The authors are grateful for the support provided by the Fundamental Research Funds for the Universities of Henan Province (NSFRF200202), State Key Laboratory of Frozen Soil Engineering (SKLFSE201917), Key Scientific and Technological Project of Henan Province (192102310503), National Key Scientific and Technological Project of Henan Province Office of Education (14B170007), China.

This is an Open Access article distributed under the terms of the Creative Commons Attribution License

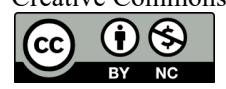

\section{References}

1. Alzoubi, M. A., Madiseh, A., Hassani, F. P., Sasmito, A. P., "Heat transfer analysis in artificial ground freezing under high seepage: validation and heatlines visualization". International Journal of Thermal Sciences, 139, 2019, pp. 232-245.

2. Hu, X., Han, Y., Yu, X., "Generalized analytical solution to steadystate temperature field of double-row-pipe freezing". Tongji Daxue Xuebao/journal of Tongji University, 43(3), 2015, pp. 386-391.

3. Yang, P., Pi, A., "Study on the effects of large groundwater flow velocity on the formation of frozen wall". Chinese Journal of Geotechnical Engineering, 23(2), 2001, pp. 167-171.

4. Rui, D. H., Wu, W. T., Zhang, H. Y., Li, G. Y., Wang, S. R., Ito, Y., "Optimization analysis of heavy metal pollutants removal from fine-grained soil by freeze-thaw and washing technology". Cold Regions Science and Technology, 173, 2020, pp. 1-10. Article ID 103025 .
5. Progulny, V., Ryabkov, M., Borysenko, K., Grachov, I., "Theoretical and experimental study of mud injection porous drainage in filters with floating loading”. Technical Journal, 12(4), 2018, pp. 231235.

6. Zhou, Z. Y., He, Y. Q., Lu, J., Zhang, X. C., "Feasibility of balcony wall-mounted solar water heating system in high-rise residential buildings". Journal of Engineering Science and Technology Review, 12(6), 2019, pp. 142-147.

7. Zhang, B., Dou, Y. Y., Hong, Q., Ji, H. H., "Numerical investigation of flow and heat transfer characteristics in plate with multiple incline stage holes". Tehnicki Vjesnik-Technical Gazette, 26(2), 2019, pp. 471-477. 
8. Yan, H., Yu, C., Chai, L. P., Li, Y. Q., Vnenkovskaia, V., Chen, H., "Design and investigation of the hydraulic performance of bionic hydrofoil based on the geometric features of sturgeons". Dyna, 94(3), 2019, pp. 278-285.

9. Pimentel, E., Sres, A., Anagnostou, G., "Large-scale Laboratory tests on artificial ground freezing under seepage-flow conditions". Geotechnique, 62 (3), 2012, pp. 227-241.

10. Sudisman, R. A., Osada, M., Yamabe, T., "Heat Transfer Visualization of the Application of Cooling Pipe in Sand with Flowing Pore Water". Journal of Cold Regions Engineering, 31(1), 2016, pp. 1-22.

11. Sudisman, R. A., Osada, M., Yamabe, T., "Experimental investigation on effects of water flow to freezing sand around vertically buried freezing pipe". Journal of Cold Regions Engineering, 33(3), 2019, pp. 1-12.

12. Li, F., Ding, H., Zhang, X., "Model test research of formation law of double-row-pipe freezing wall in water rich sand layer under seepage". Chinese Journal of Rock Mechanics and Engineering, 38(2), 2019, pp. 386-395.

13. Yang, X., Ji,Z., Zhang, P., Qi, J.,"Model test and numerical simulation on the development of artificially freezing wall in sandy layers considering water seepage". Transportation Geotechnics, 21, 2019 , pp. $1-8$

14. Wang, B., Rong, C., Cheng, H., Cai, H., Yang, F., "Temporal and spatial evolution of temperature field of single freezing pipein large velocity infiltration configuration". Cold Regions Science and Technology, 175, 2020, pp. 1-14.

15. Rouabhi, A., Jahangir, E., Tounsi, H., "Modeling heat and mass transfer during ground freezing taking into account the salinity of the saturating fluid".International Journal of Heat and Mass Transfer, 120(5), 2018, pp. 523-533.

16.Harlan, R. L., "Analysis of coupled heat-fluid transport in partially frozen soil". Water Resources Research, 9(5), 1973, pp. 13141323.

17. Vitel, M., Rouabhi, A., Tijani, M., Guerin, F., "Modeling heat transfer between a freeze pipe and the surrounding ground during artificial ground freezing activities". Computers and Geotechnics, 63, 2015, pp. 99-111.
18. Vitel, M., Rouabhi, A., Tijani, M., Guerin, F., "Modeling heat and mass transfer during ground freezing subjected to high seepage velocities". Computers and Geotechnics, 73,2016, pp. 1-15.

19. Tan, X., Chen, W., Tian, H., Cao, J., "Water flow and heat transport including ice/water phase change in porous media:Numerical simulation and application". Cold Regions Science and Technology, 68(1-2), 2011, pp. 74-84.

20. Huang, S., Guo, Y., Liu, Y., Ke, L., Liu, G., Chen, C., "Study on the influence of water flow on temperature around freeze pipes and its distribution optimization during artificial ground freezing". Applied Thermal Engineering, 135,2018, pp. 435-445.

21. Hu, R., Liu, Q., Xing, Y., "Case Study of Heat Transfer during Artificial Ground Freezing with Groundwater Flow". Water, 10, 2018, pp. 1322-1340.

22. Tounsi, H., Rouabhi, A., Jahangir, E., "Thermo-hydro-mechanical modeling of artificial ground freezing taking into account the salinity of the saturating fluid". Computers and Geotechnics, 119, 2020, pp.1-14.

23. Rui, D. H., Wu, Z. P., Ji, M. C., Liu, J. F., Wang, S. R., Ito, Y., "Remediation of $\mathrm{Cd}$ - and $\mathrm{Pb}$ - contaminated clay soils through combined freeze-thaw and soil washing". Journal of Hazardous Materials, 269, 2019, pp. 87-95.

24. Kersh, V., Kolesnikov, A., Hlitsov, M., Gedulyan, S., "Thermal and acoustic insulating gypsum composite material with improved water resistance". Technical Journal, 14(2), 2020, pp. 89-93.

25. Al-Nadawi, A. K., Salman Al-Joboory, H. N., "Three-dimensional computational fluid dynamic of heat transfer in wall with internal heat block". Journal of Engineering Science and Technology Review, 13(3), 2020, pp. 82-87.

26. Bostjan, B., Nenad, G., Samo, L., "Experimental investigation of the effect of temperature on the structures in the measurement of displacements”. Tehnicki Vjesnik-Technical Gazette, 26(4), 2019, pp. 1010-1016.

27. Plaza-Garcia, M., de-la-Macorra-Garcia, C., Magraner-Benedicto, T., "Performance of thermoactive micropile as low enthalpy geothermal heat exchanger in different seasons". Dyna, 92(2), 2017, pp. 178-182. 